\title{
Is implementation of a hospital pathway for high-flow nasal cannula initiation and weaning associated with shorter treatment duration and length of hospital stay in bronchiolitis?
}

\author{
Laura Tarantino $^{1}$, Jason Burrows ${ }^{2}$, Nathaniel Goodrich ${ }^{2}$, Ellen Kerns ${ }^{2}$, and Russell \\ $\mathrm{McCulloh}^{2}$ \\ ${ }^{1}$ Creighton University School of Medicine \\ ${ }^{2}$ Children's Hospital and Medical Center
}

September 24, 2021

\begin{abstract}
BACKGROUND: High-flow nasal cannula therapy (HFNC) is increasingly used for children with bronchiolitis, but its optimal role remains relatively uncertain. Our institution created and later revised a ward-based clinical pathway guiding initiation and weaning of HFNC. METHODS: A retrospective review of 664 encounters was conducted. Total duration of HFNC, duration of weaning from maximum flow rate, hospital length of stay (LOS), and escalation of care were compared across 3 study periods using generalized linear models: Baseline (HFNC managed at provider discretion, 5/1/2015-4/30/2017, n = 215), Intervention 1 (first pathway, initiation at $0.5 \mathrm{~L} / \mathrm{kg} / \mathrm{min}$ and escalation up to $2 \mathrm{~L} / \mathrm{kg} / \mathrm{min}, 5 / 1 / 2017-2 / 28 / 2018, \mathrm{n}=155$ ), and Intervention 2 (revised pathway, initiation at the maximum rate of $2 \mathrm{~L} / \mathrm{kg} / \mathrm{min}, 3 / 1 / 2018-1 / 31 / 2020, \mathrm{n}=294$ ). Both pathway iterations provided specific titration and weaning guidance. Models controlled for initial $\mathrm{SpO} 2$ and maximum respiratory rate to adjust for the possibility of differing case severity. RESULTS: After adjustment for severity, total duration of HFNC was significantly reduced in the second intervention, but not the first. Adjusted LOS was shorter in Intervention 1 and Intervention 2 compared to the baseline period. Adjusted weaning time and escalation of care did not differ significantly between periods. CONCLUSION: Pathway implementation was associated with modestly decreased LOS and - when initial flow rates were increased to $2 \mathrm{~L} / \mathrm{kg} / \mathrm{min}$ - reduced duration of HFNC, without differences in escalation of care or weaning time. These findings highlight the potential role of standardization of practice with clinical pathways in safely reducing unnecessary care.
\end{abstract}

\section{Hosted file}

HFNCfinal.docx available at https://authorea.com/users/435014/articles/538325-isimplementation-of-a-hospital-pathway-for-high-flow-nasal-cannula-initiation-and-weaningassociated-with-shorter-treatment-duration-and-length-of-hospital-stay-in-bronchiolitis 


\section{Qualifying Encounters}

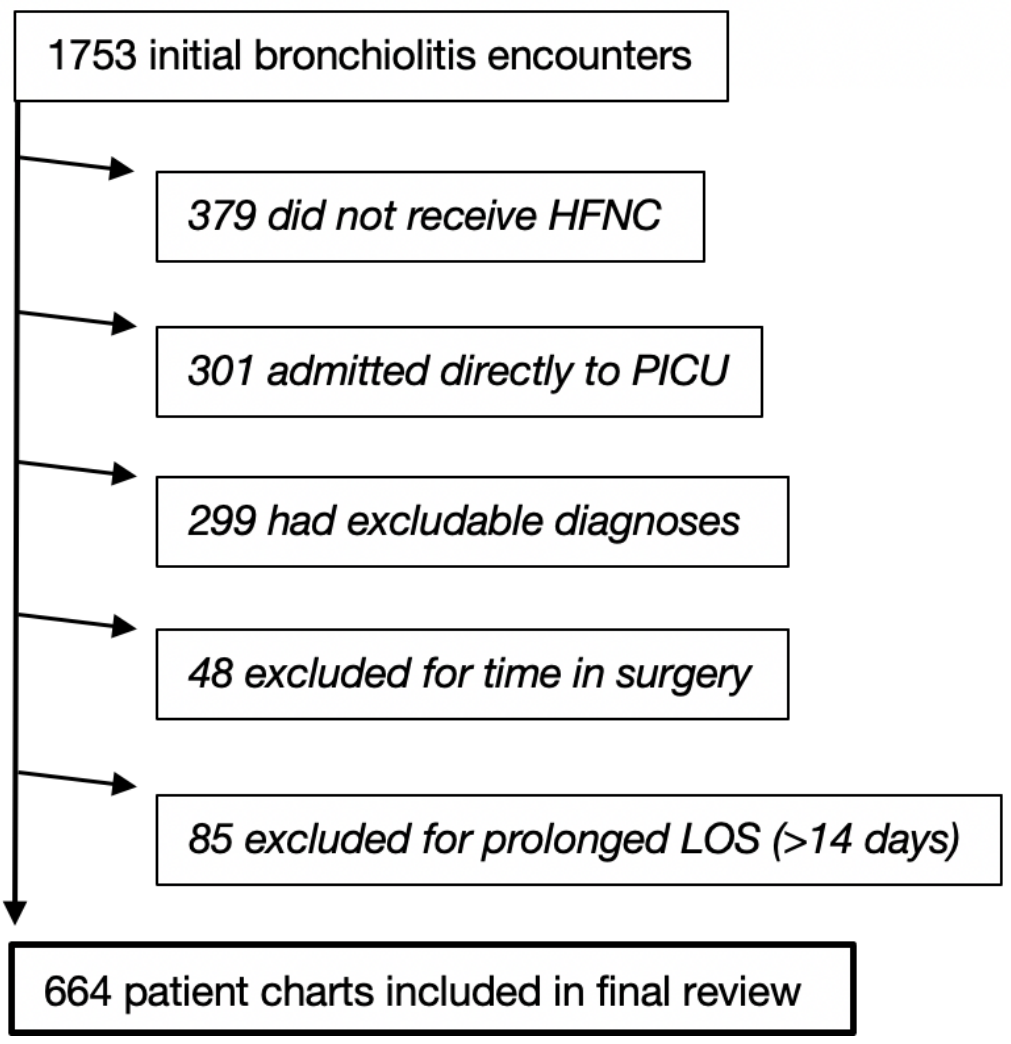




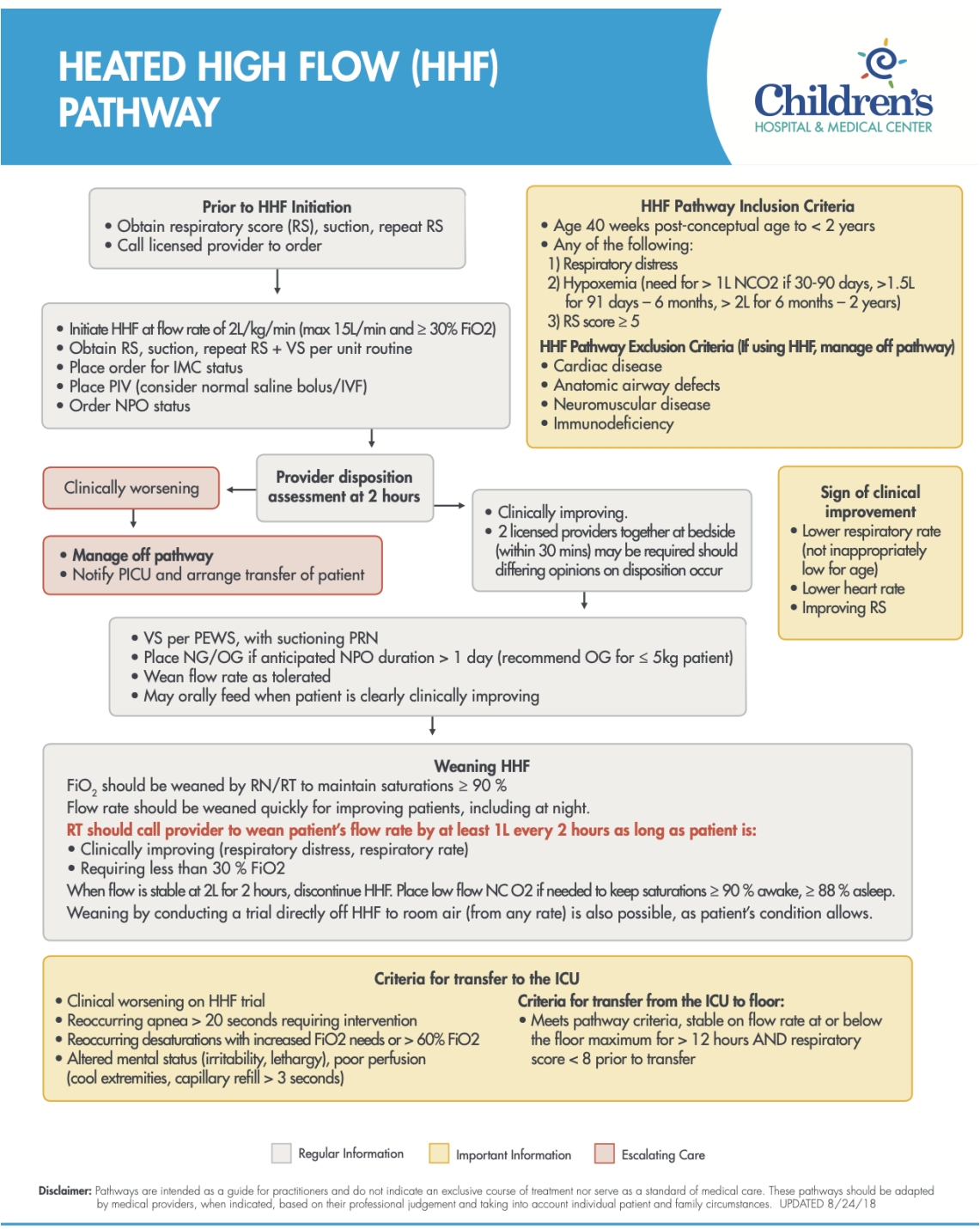

wnw.ChildrensOmaha.org/Pathways-Prolocols 


\section{Study Timeline}

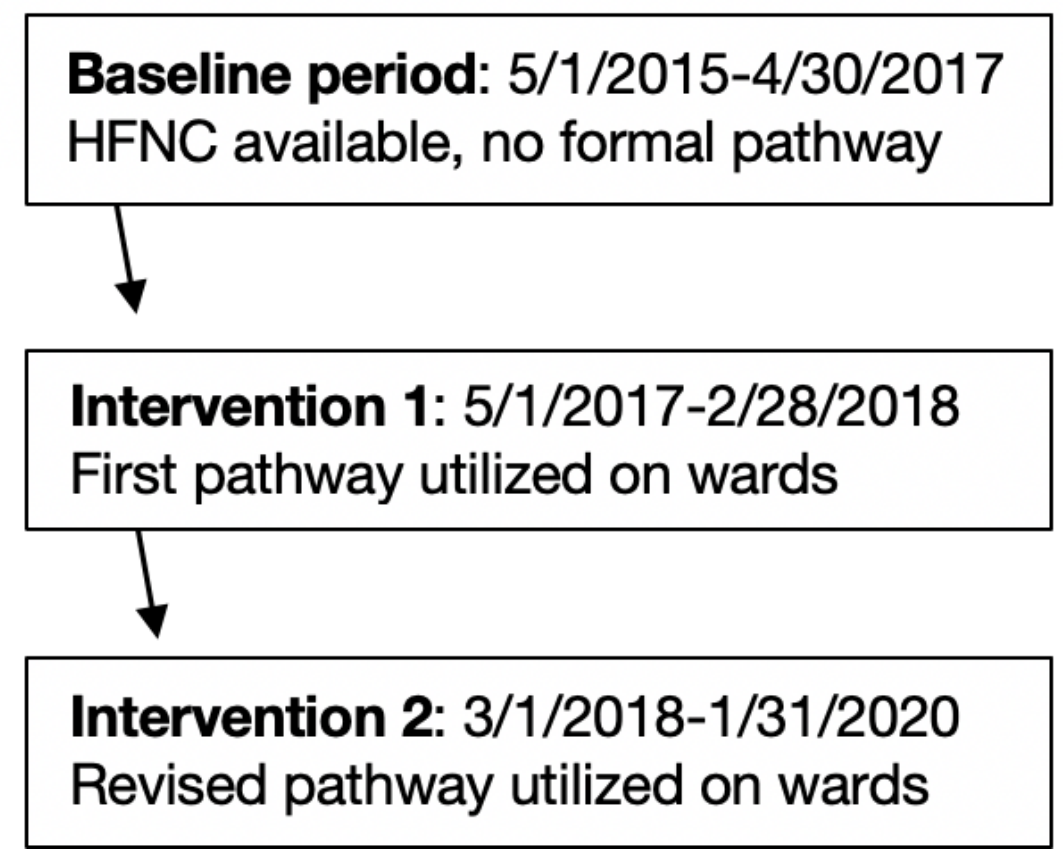

Hosted file

Table1Demographics.docx available at https://authorea.com/users/435014/articles/538325-isimplementation-of-a-hospital-pathway-for-high-flow-nasal-cannula-initiation-and-weaningassociated-with-shorter-treatment-duration-and-length-of-hospital-stay-in-bronchiolitis

Hosted file

Table20utcomes.docx available at https://authorea.com/users/435014/articles/538325-isimplementation-of-a-hospital-pathway-for-high-flow-nasal-cannula-initiation-and-weaningassociated-with-shorter-treatment-duration-and-length-of-hospital-stay-in-bronchiolitis 